\title{
Sensitivity and specificity of tuberculosis signs and symptoms screening and adjunct role of social pathology characteristics in predicting bacteriologically confirmed tuberculosis in Myanmar
}

\author{
Kyaw Ko Ko Htet ${ }^{1}$, Virasakdi Chongsuvivatwong ${ }^{2^{*}}$ (i) and Si Thu Aung ${ }^{3}$
}

\begin{abstract}
Background: Globally, using tuberculosis signs and symptoms (TB-SS) as a screening tool has become less important due to its low sensitivity and specificity. We analyzed data from the Myanmar National Tuberculosis (TB) prevalence survey in 2010. The various TB screening models were developed to predict TB by using logistic regression analysis, and their performance on TB prediction was compared by the measures of overall performance, calibration and discrimination ability, and sensitivity and specificity to determine whether social pathology characteristics could be used as a TB screening tool.

Results: Among 51,367 participants, 311 (0.6\%) had bacteriologically confirmed TB, of which 37.2\% were asymptomatic and $2 \%$ had a normal chest $X$-ray. Out of 32 various combinations of signs and symptoms, having any signs and symptoms gave the best sensitivity of $59.8 \%$ and specificity of $67.2 \%$, but chest X-ray (CXR) alone gave the highest sensitivity (95.1\%) and specificity (86.3\%). The next best combination was cough only with a sensitivity of $24.4 \%$ and specificity of $85 \%$. Other combinations had poor sensitivity $(<10 \%)$. Among various TB screening models, the overall performance $R^{2}$ was higher in the combined models of social pathology and TB signs and symptoms as well as the social pathology model, compared to TB-SS models ( $>10 \%$ versus $<3 \%$ ), although all TB screening models were perfect to predict TB (Brier score $=0)$. The social pathology model shows a better calibration, more closer to $45^{\circ}$ line of calibration plot with Hosmer-Lemeshow test $p$ value $=0.787$, than the combined models while it had a better discrimination ability in area under the curve, AUC $=80.4 \%$, compared to TB-SS models with any signs and symptoms, AUC $=63.5 \%$ and with any cough, AUC $=57.1 \%$ (DeLong $p$ value $=$ 0.0001). Moreover, at the propensity score cutoff value $\geq 0.0053$, the combined and social pathology models had sensitivity of $\sim 80 \%$ and specificity of $\sim 70 \%$. The highest population attributable fraction to predict TB by social pathology characteristics was male gender (42.6\%), age $\geq 55$ years (31.0\%), and underweight (30.4\%).

(Continued on next page)
\end{abstract}

\footnotetext{
* Correspondence: cvirasak@medicine.psu.ac.th

2Epidemiology Unit, Faculty of Medicine, Prince of Songkla University, Hat Yai 90110, Thailand

Full list of author information is available at the end of the article
}

(c) The Author(s). 2021 Open Access This article is licensed under a Creative Commons Attribution 4.0 International License, which permits use, sharing, adaptation, distribution and reproduction in any medium or format, as long as you give appropriate credit to the original author(s) and the source, provide a link to the Creative Commons licence, and indicate if changes were made. The images or other third party material in this article are included in the article's Creative Commons licence, unless indicated otherwise in a credit line to the material. If material is not included in the article's Creative Commons licence and your intended use is not permitted by statutory regulation or exceeds the permitted use, you will need to obtain permission directly from the copyright holder. To view a copy of this licence, visit http://creativecommons.org/licenses/by/4.0/. 
(Continued from previous page)

Conclusion: Over one-third of bacteriologically confirmed TB was asymptomatic. The conventional TB-SS screening tool using any TB signs and symptoms had a lower sensitivity and specificity compared to CXR and social pathology screening tools. The social pathology characteristics as TB screening tool had good calibration and can improve the discrimination ability to predict TB than TB-SS screenings and should be encouraged.

Keywords: TB signs and symptoms, Sensitivity and specificity, Social pathology, Screening

\section{Background}

Early detection and initiation of treatment of all tuberculosis (TB) patients is necessary to reduce mortality, morbidity, and transmission in the community [1]. Screening for tuberculosis signs and symptoms (TB-SS), such as cough, hemoptysis, loss of weight, chest pain, fever, night sweat, and shortness of breath, was a key component of the National TB Strategy for combating TB. In the current global practice, signs and symptoms screening is the first step for TB case finding, and those who screen positive are recommended to have a chest X-ray (CXR) and sputum smear examination [2, 3]. However, a review on the National TB prevalence survey in Asia (1990-2012) revealed that $40-79 \%$ of $\mathrm{TB}$ cases were asymptomatic [4]. Therefore, using signs and symptoms as a screening tool is still a global challenge because it happens missing TB cases in the community [5].

Globally, the slow reduction in $\mathrm{TB}$ incidence has prompted a search for a new approach in TB intervention [6]. As the current approach, TB is regarded as a medical disease. Therefore, TB screening is relying on TB-SS. In new point of view, TB is considered as the social pathology disease because it is associated with people's social, biological, and pathological characteristics [7-11]. Those characteristics included age, gender, occupation and economic status, smoking and alcohol, contact to index TB patients, human immunodeficiency virus, diabetes mellitus and malnutrition, crowding, and poor ventilation [12-21].

As people has risk of acquiring $\mathrm{TB}$ infection under relationship with social pathology characteristics, taking into account those characteristics in TB screening tool would be a potential new approach to improve TB case detection. However, performance in predicting TB case detection by using social pathology characteristics compared to TB-SS screening still needs to be evaluated. Therefore, our study was performed with the objectives of determining (i) the sensitivity and specificity of various combinations of TB-SS and (ii) the adjunctive role of social pathology characteristics in TB screening, compared with TB-SS for improving TB cases detection.

\section{Methods \\ Study design}

We revisited the data set of the National TB prevalence survey 2010, Myanmar. The analysis was done with the approval from the National Tuberculosis Programme.

\section{Study setting \\ General setting}

Myanmar is one of the 30 high TB burden countries ranking 11th globally and 4th in the South-East Asia region after India, Bangladesh, and Indonesia. In 2016 in Myanmar, an estimated 191,000 people developed TB of whom 30,000 died [22].

\section{Specific setting}

Screening and diagnostic process of participants during the National TB prevalence survey Figure 1 reveals the survey process for screening and diagnosis of TB among eligible household members during the National TB prevalence survey. Individual interviews emphasizing on TB-SS within the previous month and mobile CXR examinations were used as a parallel screening tool among survey participants for processing bacteriological examinations.

All interviewees except those with a first-trimester pregnancy were screened with CXR examinations. Pregnant women who had been excluded from the CXR examination underwent a compulsory sputum examination for smear and culture. Those suspected of having TB were screened with a CXR and if abnormal radiological findings were detected, underwent sputum examination of smear and culture.

The presumptive TB with signs and symptoms were sent for sputum examination of smear and culture after their CXR, regardless of the CXR results. The participants with both normal CXR finding and without TB-SS were categorized as normal healthy participants without continuing any confirmation test as the World Health Organization (WHO) guideline [23]. Those who did not appear at the survey site were revisited by the team, and transportation was arranged for CXR examination if necessary. Where possible, the team took sputum specimens from those who could not be screened by CXR. 


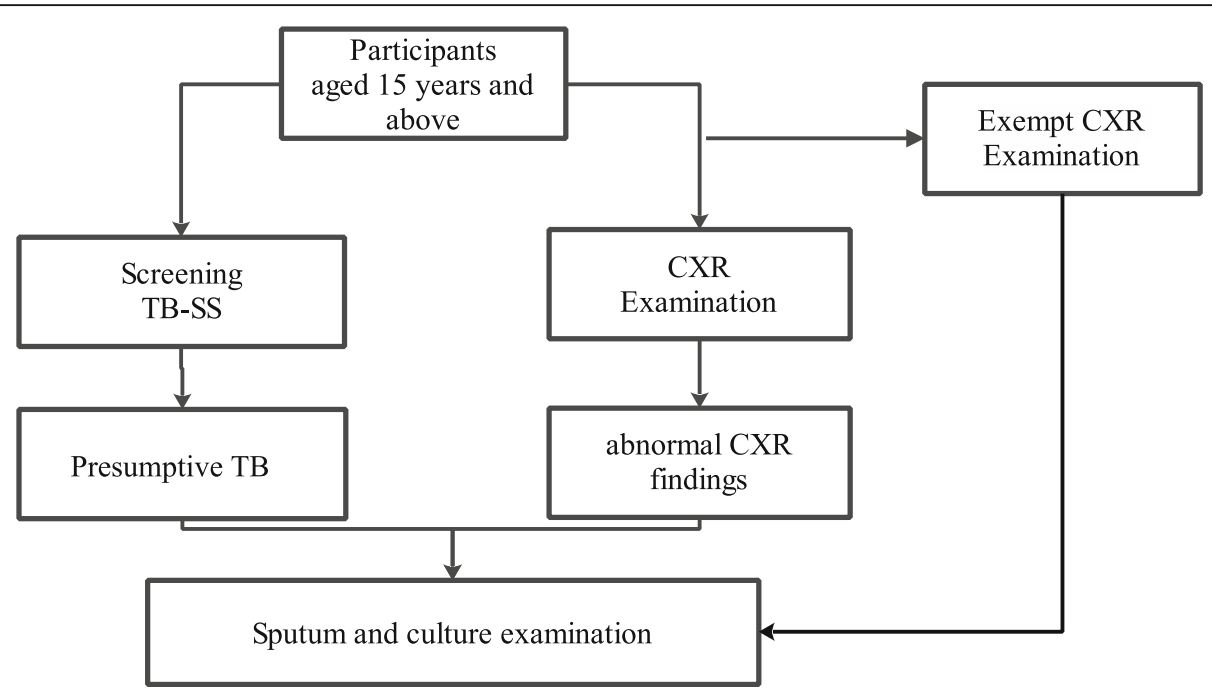

Fig. 1 Survey process for screening and diagnosis of TB among eligible participants of the household during the National TB prevalence survey. TB, tuberculosis; TB-SS, tuberculosis signs and symptoms; CXR, chest X-ray

\section{Data variables}

The main outcome variable was bacteriologically confirmed TB which is used as the gold standard for calculating the sensitivity and specificity of various combination of TB signs and symptoms and used for predicting TB by adjusting covariates.

There were 18 independent predictor variables for TB detection: (i) social characteristics: age group (years), gender, education, occupation, religion, marital status, area of residence (rural or urban), administrative division (region or state), smoking and drinking, contact with a known TB case, previous history of TB but no current treatment; (ii) pathology characteristics: body mass index $\left(\mathrm{kg} / \mathrm{m}^{2}\right)$, diabetes mellitus, hypertension, and human immunodeficiency virus (HIV). The 14 administrative divisions of Myanmar were classified into two groups based on whether the majority of people living there were of Bamar ethnicity (region) or belonged to an ethnic minority group (state). Body mass index was categorized as underweight $\left(<18.5 \mathrm{~kg} / \mathrm{m}^{2}\right)$, normal $\left(18.5-24.9 \mathrm{~kg} / \mathrm{m}^{2}\right)$, and overweight/obese $\left(\geq 25 \mathrm{~kg} / \mathrm{m}^{2}\right)$ [24] and (iii) TB-SS included cough, hemoptysis, recent loss of weight, chest pain, and fever within previous 1 month. If one of the TB-SS was present, it was regarded as any TB signs and symptoms variable. If there was cough with any duration but does not have any other symptoms, it was defined as any cough variable.

\section{Data analysis and statistics}

The data was analyzed in $\mathrm{R}$ studio using $\mathrm{R}$ version 4.0.0 (the $\mathrm{R}$ foundation for Statistical Computing) [25]. The prevalence of bacteriologically confirmed TB was summarized per 100,000 population based on TB signs and symptoms and chest X-ray as a parallel screening tool.
The situation of TB was tabulated against various combinations of TB-SS. The sensitivity and specificity of various combined TB-SS to predict TB were computed, and $95 \%$ confidence interval (CI) was included by using bootstrap method (resampling $=500$ ) [26]. The positive likelihood ratio was also presented for each combination of TB-SS. TB-SS variables with high sensitivity were selected for further analysis. Choosing TB-SS with high sensitivity was to be comparable with social pathology characteristics for assessing which one had a better TB prediction on using as the TB screening tool.

To find out role of social pathology characteristics on TB prediction, this study was analyzed in accordance with guidelines for transparent reporting of a multivariable prediction model for individual prognosis or diagnosis (TRIPOD) statement for prediction studies [27].

\section{Developing various TB screening models}

The various TB screening models were developed to predict the bacteriologically confirmed TB: (i) combined models which include all social pathology characteristics and TB-SS variables with high sensitivity, (ii) social pathology model which include all social pathology characteristics variables, and (iii) TB-SS models which include TB-SS variables with high sensitivity.

\section{Selecting candidate predictor variables for each TB screening model}

For each TB screening model, association between predictor variables and bacteriologically confirmed TB was assessed by using chi-square test in a univariate analysis. Multivariate logistic regression analysis was performed to develop a predictive model of TB by including variables with the significant $p$ value $\leq 0.2$ in univariate 
analysis. The final multivariate model was chosen by stepwise backward method using Akaike information criterion (AIC). The model with the lowest AIC was the best for TB prediction. The significant level of variables to predict TB was set at $p$ value $<0.05$ [28].

The population attributable fraction (PAF) for each predictor variable was also calculated to assess the public health impact of social pathology characteristics in population for TB occurrence by using Miettinen's formula [29] which is defined as follows:

$$
\mathrm{PAF}=\frac{p \times(\text { ORadj }-1)}{\text { ORadj }}
$$

where $p$ is the prevalence of TB for each predictor variable and ORadj is the adjusted odds ratio determined from the logistic regression model.

\section{Calculating predicted probability of propensity score for $T B$ risk in each TB screening model}

In each TB screening tool, the regression coefficients of the significant variables in the final multivariate logistic regression model were used to drive a propensity score which is the conditional predicted probability of being diagnosed with a specific disease given values of covariates [30]. The propensity score summarizes all the relevant characteristics to predict disease in a single composite score [31]. Each participant was allocated with propensity score. The mathematical equation for calculating the propensity score from regression coefficients of the final logistic regression model was as follows [30]:

$$
\begin{aligned}
\text { Propensity score }= & (\exp (\beta 0+\beta 1 \mathrm{X} 1+\ldots+\beta \mathrm{pXp})) \\
& /(1+\exp (\beta 0+\beta 1 \mathrm{X} 1+\ldots+\beta \mathrm{pXp}))
\end{aligned}
$$

\section{Assessing the performance of each TB screening model to detect $T B$}

To highlight the role of social pathology characteristics on TB screening, the performance of TB screening models were compared by measures of overall performance, calibration, and discrimination ability of propensity score to predict TB [32].

The overall performance of a TB screening tool was measured for the difference between the observed outcome and predicted probability of propensity score in TB by using the Nagelkerke $\mathrm{R}^{2}$ and Brier score [32]. Nagelkerke $R^{2}$ explains variations of TB prediction by a model [33]. The Brier score ranges from 0 for a perfect model to 0.25 for a non-informative model to predict TB [34].

A model calibration for assessing the degree of consistency between observed outcome and predicted probability of propensity score in $\mathrm{TB}$ screening tool was performed based on the Hosmer-Lemeshow goodness-of-fit test with measurements of maximum absolute error (Emax) and mean absolute error (Eavg) as well as visually by plotting the observed TB cases against the predicted probability of propensity score in $\mathrm{TB}$ by $10 \%$ risk of stratification level [32, 35, 36]. A good calibration is when Hosmer-Lemeshow test yielded nonsignificant statistical value, as well as Emax and Eavg is zero, indicating no error or no difference between observed data and predicted propensity score value [37]. The calibration plot includes an intercept, which indicates the extent that predictions are systematically too low or too high "calibration-inthe-large," and a calibration slope [36]. Having an intercept as zero and a slope as one indicates that the model is fit with perfect prediction of propensity score on the $45^{\circ}$ line of plot [32].

Discrimination ability of propensity score between participants with and without TB in each TB screening model was assessed by using a receiver operator characteristic curve (ROC) analysis with area under the curve (AUC) or c-statistic [32]. The ROC curve shows the tradeoff between the sensitivity and the specificity of a classifier for various choices of the probability threshold of propensity score to binary outcome of bacteriologically confirmed TB. The AUC or c-statistics indicate the rank correlation between predicted probabilities of outcome occurring and the observed response. If ROC curve is close to upper left corner of the plot (sensitivity $=100$ and specificity $=$ $100 \%)$, then AUC or c-statistics closes to $100 \%$. An AUC or c-statistic of $<70 \%$ represents poor discrimination while $80-90 \%$ indicates excellent discrimination [38]. The $p$ value $<0.05$ of DeLong's test was used to show the significant difference in the AUC of models. In addition to AUC statistic, discrimination slope was calculated for how participants were separated with and without the TB by measuring difference in average predicted probability of propensity score to TB between them and also visually by box plot to show overlapping of predicted probability of propensity score between participants with and without TB $[32,39]$.

\section{Model validation}

Special focus was given to the influence of TB screening by social pathology characteristics. Therefore, internal validity of the final multivariate model with significant social pathology characteristic variables was assessed by bootstrap method (resampling $=500$ ) [27]. To assess model fit and optimism, bootstrapped estimates of overall performance, calibration, and discrimination were compared with the original model's estimates. 
Sensitivity, specificity, and positive likelihood ratio of different propensity score cutoff values for various $T B$ screening models by using bacteriologically confirmed $T B$ as gold standard

The different cutoff values of propensity score in combined models and social pathology TB screening model were tabulated against bacteriologically confirmed TB as gold standard to calculate the sensitivity, specificity, and positive likelihood ratio which were compared with TBSS models.

\section{Results}

Prevalence of bacteriologically confirmed TB summarized by TB signs and symptoms (TB-SS) and chest X-ray (CXR) as a parallel screening tool

Table 1 shows the ability of any TB-SS and CXR in detecting bacteriologically confirmed TB. Overall, 311 out of 51,367 participants had bacteriologically confirmed $\mathrm{TB}$, equating to 605 cases per 100,000 populations. Almost all bacteriologically confirmed TB were initially detected in CXR screening, but $6(1.9 \%)$ had a normal CXR. Of the 311 bacteriologically confirmed TB, 116 (37.3\%) were asymptomatic.

Sensitivity, specificity, and positive likelihood ratio of various combinations of TB-SS by using bacteriologically confirmed TB as the gold standard

Table 2 shows the sensitivity, specificity, and positive likelihood ratio of various combinations of TB-SS by using bacteriologically confirmed TB as the gold standard. The table is sorted in descending order of frequency of occurrence. Out of 32 various combinations of TB-SS, having any signs and symptoms gave the most meaningful sensitivity of 59.8\% (bootstrapped 95\% CI 54.1-65.3) and specificity of $67.2 \%$ (bootstrapped 95\% CI 66.767.2), but it was lower than CXR alone (sensitivity = $95.1 \%$ and specificity $=86.3 \%$, shown in Table 1 ). The combination with the next best accuracy was any cough with a sensitivity of $24.4 \%$ (bootstrapped $95 \%$ CI $19.7-$ 29.6) and specificity of $85 \%$ (bootstrapped 95\% CI $85.5-$
86.1). The positive likelihood ratio $>1$ result is the evidence to have positive bacteriologically confirmed TB if any TB signs and symptoms or cough is present. The remaining combinations of TB-SS had poor sensitivity $(<10 \%)$ compared to any TB-SS and any cough. The TB-SS having persistent cough $>2$ weeks and other symptoms including night sweet also had the sensitivity of $8.4 \%$ and $5.8 \%$ and the specificity of $98.3 \%$ and $95.2 \%$, respectively).

\section{Selecting candidate predictor variables for various TB screening models}

Table 3 shows univariate predictor variables associated with bacteriologically confirmed TB. Out of 18 predictor variables, 15 variables showed significant association with $\mathrm{TB}$ in univariate analysis and then included in the multivariate analysis of each TB screening model.

Table 4 reveals that the five TB screening models, A to $\mathrm{E}$, were developed to predict $\mathrm{TB}$ by logistic regression analysis. Models A and B were the combined models including the significant social pathology characteristics and TB-SS variables (any TB signs and symptoms and any cough, respectively), and model $\mathrm{C}$ was our proposed social pathology model including significant social pathology characteristic variables while model $\mathrm{D}$ and $\mathrm{E}$ were TB-SS models including any TB signs and symptoms variable and any cough variable, respectively.

In the final multivariate analysis, the combined models (A and B) were the best fit with AIC = 3331 and AIC = 3373 , respectively while social pathology model (C) was the best fit with AIC $=3382$ for TB prediction. The significant social pathology characteristic variables associated with TB in models $\mathrm{A}, \mathrm{B}$, and $\mathrm{C}$ were the same such as higher age group (years), being male, dependent, other religion, living in urban area of residence, living in state administrative division, having contact with a known case of $\mathrm{TB}$, having previous history of $\mathrm{TB}$, and underweight. Table 5 shows that the three factors having the highest population attributable fraction to predict

Table 1 Distribution of bacteriologically confirmed TB detected using chest X-ray abnormality and any tuberculosis signs and symptoms as parallel screening tools

\begin{tabular}{|c|c|c|c|c|c|}
\hline \multirow[t]{2}{*}{ Screening tools } & & \multirow{2}{*}{$\begin{array}{l}\text { Total } \\
(N= \\
51 \\
367)\end{array}$} & \multicolumn{2}{|c|}{ Bacteriologically confirmed TB (n) } & \multirow{3}{*}{$\begin{array}{l}\text { Bacteriologically } \\
\text { confirmed TB } \\
\text { (rate per } 100, \\
000 \text { population) }\end{array}$} \\
\hline & & & Positive & Negative & \\
\hline & & & $N=311$ & $N=51,056$ & \\
\hline Chest X-ray abnormality & Any TB signs and symptoms & & & & \\
\hline- & - & 28,878 & 0 & $28,878^{\mathrm{a}}$ & 0 \\
\hline- & + & 11,852 & 6 & 11,846 & 50 \\
\hline+ & - & 5,555 & 116 & 5,439 & 2,088 \\
\hline+ & + & 5,082 & 180 & 4,902 & 3,541 \\
\hline
\end{tabular}

${ }^{2}$ Those participants were categorized as normal healthy participants without proceeding any TB confirmation test as WHO guideline [23] 
Table 2 Sensitivity, specificity, and positive likelihood ratio of various combinations of TB-SS by using bacteriologically confirmed TB as the gold standard

\begin{tabular}{|c|c|c|c|c|c|c|c|c|c|c|c|c|c|}
\hline \multirow[t]{3}{*}{ Category $^{a}$} & \multirow[t]{3}{*}{ Cough } & \multirow[t]{3}{*}{ Hemoptysis } & \multirow{3}{*}{$\begin{array}{l}\text { Recent } \\
\text { weight } \\
\text { loss }\end{array}$} & \multirow{3}{*}{$\begin{array}{l}\text { Chest } \\
\text { pain }\end{array}$} & \multirow[t]{3}{*}{ Fever } & \multirow{3}{*}{$\begin{array}{l}\text { Total } \\
(N)\end{array}$} & \multicolumn{6}{|c|}{ Bacteriologically confirmed TB } & \multirow{3}{*}{$\begin{array}{l}\text { Positive } \\
\text { likelihood } \\
\text { ratio }\end{array}$} \\
\hline & & & & & & & \multicolumn{3}{|c|}{ Positive $(N=311)$} & \multicolumn{3}{|c|}{ Negative $(N=51,056)$} & \\
\hline & & & & & & & $\bar{n}$ & $\begin{array}{l}\text { Sensitivity } \\
(\%)\end{array}$ & $\begin{array}{l}95 \% \\
\mathrm{Cl}\end{array}$ & $n$ & $\begin{array}{l}\text { Specificity } \\
(\%)\end{array}$ & $\begin{array}{l}95 \% \\
\mathrm{Cl}\end{array}$ & \\
\hline 1 & $\begin{array}{l}\text { Any TB signs and } \\
\text { symptom }\end{array}$ & & & & & $\begin{array}{l}16 \\
934\end{array}$ & 186 & 59.8 & $\begin{array}{l}54.1- \\
65.3\end{array}$ & $\begin{array}{l}16 \\
748\end{array}$ & 67.2 & $\begin{array}{l}66.7- \\
67.6\end{array}$ & 1.8 \\
\hline 2 & + & - & - & - & - & 7306 & 76 & 24.4 & $\begin{array}{l}19.7- \\
29.6\end{array}$ & 7230 & 85.8 & $\begin{array}{l}85.5- \\
86.1\end{array}$ & 1.7 \\
\hline 3 & - & - & - & + & - & 2861 & 8 & 2.6 & $\begin{array}{l}1.1- \\
5.0\end{array}$ & 2853 & 94.4 & $\begin{array}{l}94.2- \\
94.6\end{array}$ & 0.5 \\
\hline 4 & + & - & - & + & - & 2312 & 26 & 8.4 & $\begin{array}{l}5.5- \\
12.0\end{array}$ & 2286 & 95.5 & $\begin{array}{l}95.3- \\
95.7\end{array}$ & 1.8 \\
\hline 5 & + & - & - & - & + & 1005 & 12 & 3.9 & $\begin{array}{l}2.0- \\
6.6\end{array}$ & 993 & 98.1 & $\begin{array}{l}97.9- \\
98.2\end{array}$ & 1.9 \\
\hline 6 & - & - & - & - & + & 819 & 9 & 2.9 & $\begin{array}{l}1.3- \\
5.4\end{array}$ & 810 & 98.4 & $\begin{array}{l}98.3- \\
98.5\end{array}$ & 1.7 \\
\hline 7 & + & - & - & + & + & 598 & 11 & 3.5 & $\begin{array}{l}1.7- \\
6.2\end{array}$ & 587 & 98.9 & $\begin{array}{l}98.7- \\
98.9\end{array}$ & 1.8 \\
\hline 8 & - & - & + & - & - & 410 & 8 & 2.6 & $\begin{array}{l}1.1- \\
5.0\end{array}$ & 402 & 99.2 & $\begin{array}{l}99.1- \\
99.3\end{array}$ & 3.2 \\
\hline 9 & + & - & + & + & - & 401 & 8 & 2.6 & $\begin{array}{l}1.1- \\
5.0\end{array}$ & 393 & 99.5 & $\begin{array}{l}99.4- \\
99.6\end{array}$ & 3.3 \\
\hline 10 & - & - & - & + & + & 299 & 1 & 0.3 & $\begin{array}{l}0.0- \\
1.7\end{array}$ & 298 & 99.4 & $\begin{array}{l}99.3- \\
99.5\end{array}$ & 0.5 \\
\hline 11 & - & - & + & + & - & 168 & 0 & 0 & $\begin{array}{l}0.0- \\
1.1\end{array}$ & 168 & 99.6 & $\begin{array}{l}99.5- \\
99.7\end{array}$ & 0.0 \\
\hline
\end{tabular}

"+" presence, "_" absence, 95\% Cl 95\% confidence interval (Bootstrap resampling $=500$ )

${ }^{a}$ The remaining 21 categories, which had a sensitivity of $<10 \%$ and specificity of $\sim 99 \%$, are not shown

TB were male gender (42.6\%), age $\geq 55$ years $(31.0 \%)$, and underweight (30.4\%).

\section{Calculating predicted probability of propensity score for TB risk in each TB screening model}

Table 4 shows that the predicted probability of propensity score for bacteriologically confirmed TB for each TB screening model was derived from coefficients of significant variables in final multivariate regression analysis.

\section{Assessing the performance of each TB screening model to detect TB by using predicted propensity score}

Table 6 shows overall performance, calibration, and discrimination ability of predicted propensity score in various TB screening models to predict bacteriologically confirmed TB. Figures 2a, 3a, and 4a show virtual plot for calibration and discrimination slope of box plot for TB screening models A to E while Figs. 2b, $3 \mathrm{~b}$, and $4 \mathrm{~b}$ were plots for internal validation of the proposed social pathology model $\mathrm{C}$ (bootstrap resampling $=500$ ).

The overall performance $\mathrm{R}^{2}$ was high in combined models (A, 12.9\% and B, 11.8\%) and social pathology model $(\mathrm{C}, 11.5 \%)$ while it was low in TB-SS models (D,
$2.7 \%$ and E, $0.6 \%$ ). Brier score was close to zero, indicating all models were perfect and informative to predict bacteriologically confirmed TB.

Figure 2a shows that a better calibration, more closer to $45^{\circ}$ line of plot, was observed in the social pathology model (C) and TB-SS models (D and E), compared to combined models (A and B). In the original and validated bootstrapping social pathology models $(\mathrm{C})$, the Hosmer-Lemeshow test yielded nonsignificant statistics ( $p$ value $=0.787$ and 0.502 , respectively) with zero in Eavg, Emax, and intercept and one in slope, suggesting that there was no departure from perfect fit between prediction and observed value.

Figure $3 \mathrm{a}$ reveals that the discrimination ability was excellent in combined models $(\mathrm{A}, \mathrm{AUC}=81.7 \%$ and $\mathrm{B}$, AUC $=80.7 \%)$ and social pathology model $(\mathrm{C}, \mathrm{AUC}=$ 80.5\% with bootstrapped 95\% CI 78.3-83.0\%) while it was poor in TB-SS models (D, AUC $=63.7 \%$ and $\mathrm{E}$, AUC $=55.2 \%)$. The social pathology model showed little evidence of overfitting that is optimism in estimated AUC between original and validated bootstrapping model was 0.003 . The social pathology model significantly improved the discrimination ability, compared to TB-SS models (DeLong $p$ value $=0.0001$ ) 
Table 3 Predictor variables associated with bacteriologically confirmed TB in univariate analysis

\begin{tabular}{|c|c|c|c|c|}
\hline \multirow[t]{2}{*}{ Predictor variables } & \multicolumn{2}{|c|}{ Bacteriologically confirmed TB } & \multirow[t]{2}{*}{ Total } & \multirow{2}{*}{$\begin{array}{l}P \\
\text { value }\end{array}$} \\
\hline & Negative & Positive & & \\
\hline Total & 51,056 & 311 & 51,367 & \\
\hline
\end{tabular}

\section{Social characteristics}

Age group (years)

$$
<0.001
$$$$
\text { 15-24 }
$$

$11,888(23.3)$

$11(3.5)$

25-34

$11,172(21.9)$

$52(16.7)$

11,899 (23.2)

35-44

10,386 (20.3)

$76(24.4)$

$11,224(21.9)$

45-54

8214 (16.1)

$66(21.2)$

$10,462(20.4)$

$55+$

9396 (18.4)

106 (34.1)

$8280(16.1)$

Gender

Female

$28,868(56.5)$

Male

$22,188(43.5)$

105 (33.8)

$<0.001$

Education

Illiterate

5569 (10.9)

Read and write

5027 (9.8)

Primary

$19,481(38.2)$

Middle

$11,184(21.9)$

High

6549 (12.8)

University

$1157(2.3)$

Graduate

$2089(4.1)$

$206(66.2)$

$<0.001$

Occupation

Non farmer

17,677 (34.6)

55 (17.7)

37 (11.9)

91 (29.3)

9502 (18.5)

Farmer

Dependent

22,784 (44.6)

10,595 (20.8)

66 (21.2)

44 (14.1)

3 (1)

15 (4.8)

$<0.001$

Religion

Buddhist

$46,839(91.7)$

Other religion

$4217(8.3)$

Marital status

Single

$14,914(29.2)$

Married

Separated/divorced

31,669 (62)

$714(1.4)$

Widow/widower

$3759(7.4)$

Area of residence

Rural

39,905 (78.2)

Urban

$11,151(21.8)$

105 (33.8)

$113(36.3)$

93 (29.9)

$<0.001$

263 (84.6)

48 (15.4)

$<0.001$

Administrative division

Region

36,971 (72.4)

39 (12.5)

28,973 (56.4)

22,394 (43.6)

$5624(10.9)$

$5064(9.9)$

19,572 (38.1)

$11,250(21.9)$

6593 (12.8)

$1160(2.3)$

$2104(4.1)$

17,782 (34.6)

22,897 (44.6)

$10,688(20.8)$

47,102 (91.7)

$4265(8.3)$

14,953 (29.1)

$226(72.7)$

31,895 (62.1)

$6(1.9)$

720 (1.4)

40 (12.9)

$3799(7.4)$

$208(66.9)$

$<0.001$

State

14,085 (27.6)

$192(61.7)$

$<0.001$

Smoking

Never smoked

Smoked in the past

$33,412(65.4)$

$119(38.3)$

$<0.001$

Current smoker

3016 (5.9)

135 (43.4)

49 (15.8)

40,113 (78.1)

$11,254(21.9)$

37,163 (72.3)

14,204 (27.7)

33,547 (65.3)

14,628 (28.7)

$127(40.8)$

3065 (6.0)

14,755 (28.7) 
Table 3 Predictor variables associated with bacteriologically confirmed TB in univariate analysis (Continued)

\begin{tabular}{|c|c|c|c|c|}
\hline \multirow[t]{2}{*}{ Predictor variables } & \multicolumn{2}{|c|}{ Bacteriologically confirmed TB } & \multirow[t]{2}{*}{ Total } & \multirow{2}{*}{$\begin{array}{l}P \\
\text { value }\end{array}$} \\
\hline & Negative & Positive & & \\
\hline Drank in the past & $2957(5.8)$ & 49 (15.8) & $3006(5.9)$ & \\
\hline Current drinker & $8022(15.7)$ & $71(22.8)$ & $8093(15.8)$ & \\
\hline Contact with a known TB case & & & & $<0.001$ \\
\hline No & $47,425(93.3)$ & $265(85.8)$ & $47,690(93.3)$ & \\
\hline Yes & $3389(6.7)$ & $44(14.2)$ & $3433(6.7)$ & \\
\hline Previous history of TB & & & & $<0.001$ \\
\hline No & $49,635(97.2)$ & $269(86.5)$ & $49,904(97.2)$ & \\
\hline Yes & $1421(2.8)$ & $42(13.5)$ & $1463(2.8)$ & \\
\hline \multicolumn{5}{|l|}{ Pathological characteristics } \\
\hline Body mass index (kg/m2) & & & & $<0.001$ \\
\hline Normal & $32,821(64.3)$ & $149(47.9)$ & $32,970(64.2)$ & \\
\hline Underweight & $11,689(22.9)$ & $147(47.3)$ & $11,836(23.1)$ & \\
\hline Overweight/obese & $6511(12.8)$ & $15(4.8)$ & $6526(12.7)$ & \\
\hline History of diabetes mellitus & & & & 0.153 \\
\hline No & $50,676(99.3)$ & $306(98.4)$ & $50,982(99.3)$ & \\
\hline Yes & $380(0.7)$ & $5(1.6)$ & $385(0.7)$ & \\
\hline History of hypertension & & & & 0.404 \\
\hline No & $45,646(89.4)$ & $273(87.8)$ & $45,919(89.4)$ & \\
\hline Yes & $5410(10.6)$ & $38(12.2)$ & $5448(10.6)$ & \\
\hline History of HIV & & & & 1 \\
\hline No & $51,047(100)$ & $311(100)$ & $51,358(100)$ & \\
\hline Yes & $9(0)$ & $0(0)$ & $9(0)$ & \\
\hline \multicolumn{5}{|l|}{ TB-SS } \\
\hline Any TB signs and symptoms & & & $<0.001$ & \\
\hline Absence & $34,308(67.2)$ & $125(40.2)$ & $34,433(67)$ & \\
\hline Presence & $16,748(32.8)$ & $186(59.8)$ & $16,934(33)$ & \\
\hline Any cough & & & & $<0.001$ \\
\hline Absence & $43,826(85.8)$ & $235(75.6)$ & $44,061(85.8)$ & \\
\hline Presence & $7230(14.2)$ & $76(24.4)$ & $7306(14.2)$ & \\
\hline
\end{tabular}

HIV human immunodeficiency virus, TB tuberculosis, TB-SS tuberculosis signs and symptoms

In Fig. 4a, the discrimination slope in box plot shows that overlapping the predicted probability of propensity score between participants with and without TB was less likely to be in combined models (A and B) and social pathology model $(C)$ while it was more likely to be in TB-SS models (D and E). The discrimination slope of the social pathology model (C) was 0.015 with bootstrapped $95 \%$ CI 0.004 to 0.018 .

Sensitivity, specificity, and positive likelihood ratio of different propensity score cutoff values in various TB screening models by using bacteriologically confirmed TB as the gold standard

Table 7 shows the propensity score of 0.0053 and above cutoff level in combined models (A and B), and social model $(\mathrm{C})$ had higher sensitivity, $\sim 80 \%$ to predict TB compared to TB-SS models (D, 59.8\% and E, 24.4\%) while those had the specificity, $~ 70 \%$ higher than the TB-SS model with any TB-SS variable (D, 67\%). The propensity score cutoff level used to define high-risk increases, the sensitivity decreases but the positive likelihood ratio increases, indicating that the screening test of the proposed social pathology model could be used to clearly rule-in or rule-out the risk of TB.

\section{Discussion}

Almost all bacteriologically confirmed $\mathrm{TB}$ were initially detected in CXR screening but only $2 \%$ of confirmed cases were missed. Over one third of TB cases were asymptomatic. The conventional TB-SS screening tool 
Table 4 Various TB screening models to predict bacteriologically confirmed TB in logistic regression analysis

\begin{tabular}{|c|c|c|}
\hline \multirow[t]{3}{*}{ Predictor variables } & \multicolumn{2}{|c|}{ Various TB screening models to predic } \\
\hline & \multicolumn{2}{|c|}{ Combined models } \\
\hline & $\bar{A}$ & B \\
\hline \multicolumn{3}{|c|}{ I. Predictor variables to predict bacteriologically confirmed TB in univariate anal } \\
\hline $\begin{array}{l}\text { (1) All social pathology characteristics } \\
\text { variables }\end{array}$ & + & + \\
\hline (2) Any TB signs and symptoms variable & + & \\
\hline (3) Any cough variable & & + \\
\hline
\end{tabular}

\section{Social pathology TB-SS models}

model

C

D E

II. Coefficient $(\beta)$ of significant predictor variables to predict bacteriologically confirmed TB in final multivariate logistic regression analysis

Intercepts

Social characteristics

Age group (years)

$$
\text { 15-24 }
$$

25-34

$35-44$

45-54

$55+$

Gender

Female

Male

Occupation

Non farmer

Farmer

Dependent

Religion

Buddhist

Other

Area of residence

Rural

Urban

Administrative division

Region

State

Contact with a known TB case

No

Yes

Previous history of TB

No

Yes

Pathology characteristic

Body mass index

Underweight
Normal
Overweight/obese

TB-SS
$-8.7262$

$-8.5302$

$-8.4746$

$-5.6148$

$-5.22840$

$\begin{array}{lll}0.0000 & 0.0000 & 0.0000 \\ 1.7756 & 1.8222 & 1.8248 \\ 2.3192 & 2.3699 & 2.3756 \\ 2.3008 & 2.3831 & 2.3916 \\ 2.2943 & 2.3852 & 2.4088\end{array}$

0.0000

0.0000

0.0000

1.0400

1.0261

1.0436

0.0000

0.0000

0.0000

$-0.2440$

$-0.2198$

$-0.2130$

0.4153

0.4241

0.4323

0.0000

0.0000

0.0000

0.4001

0.4663

0.4893

0.0000

0.0000

0.0000

0.5039

0.4673

0.4520

0.0000

0.0000

0.0000

0.3727

0.4529

0.4664

0.0000

0.0000

0.0000

0.6562

0.7116

0.7214

0.0000

0.0000

0.0000

0.9422

1.0226

1.0313

$\begin{array}{lll}0.9923 & 1.0379 & 1.0519 \\ 0.0000 & 0.0000 & 0.0000 \\ -0.8556 & -0.9038 & -0.9069\end{array}$


Table 4 Various TB screening models to predict bacteriologically confirmed TB in logistic regression analysis (Continued)

\begin{tabular}{|c|c|c|c|c|c|}
\hline \multirow[t]{3}{*}{ Predictor variables } & \multicolumn{5}{|c|}{ Various TB screening models to predict bacteriologically confirmed TB } \\
\hline & \multicolumn{2}{|c|}{ Combined models } & \multirow{2}{*}{$\begin{array}{l}\text { Social pathology } \\
\text { model } \\
\text { C }\end{array}$} & \multicolumn{2}{|l|}{ TB-SS models } \\
\hline & $\bar{A}$ & B & & $\overline{\mathrm{D}}$ & $\mathrm{E}$ \\
\hline \multicolumn{6}{|l|}{ Any TB signs and symptoms } \\
\hline Absence & 0.0000 & & & 0.0000 & \\
\hline Presence & 0.8601 & & & 1.1145 & \\
\hline \multicolumn{6}{|l|}{ Any cough } \\
\hline Absence & & 0.0000 & & & 0.0000 \\
\hline Presence & & 0.4682 & & & 0.67314 \\
\hline AIC & 3331.4 & 3373 & 3382.1 & 3706.3 & 3777.8 \\
\hline Median (IQR) of propensity score & $\begin{array}{l}0.003(0.001- \\
0.006)\end{array}$ & $\begin{array}{l}0.003(0.001- \\
0.007)\end{array}$ & $0.003(0.001-0.006)$ & $\begin{array}{l}0.003(0.002- \\
0.01)\end{array}$ & $\begin{array}{l}0.005(0.004- \\
0.006)\end{array}$ \\
\hline
\end{tabular}

All social pathology variables included age, gender, education, occupation, religion, marital status, area of residence (rural or urban), administrative division (region or state), smoking and drinking, contact with a known TB case, previous history of TB, body mass index $\left(\mathrm{kg} / \mathrm{m}^{2}\right)$, diabetes mellitus, human immunodeficiency virus and hypertension. Variables included in univariate analysis of each TB screening model are indicated by " + ". The propensity score for each model was calculated from coefficient ( $\beta$ ) of significant predictor variables in each TB screening model

AIC Akaike information criterion, IQR interquartile range, TB tuberculosis, TB-SS TB signs and symptoms

using any TB signs and symptoms had low sensitivity and specificity, compared to using CXR and social pathology characteristic screening tools. Use of social pathology characteristics regardless of TB-SS in a predictive model had good calibration and could outperform in discrimination ability to predict $\mathrm{TB}$ compared to any $\mathrm{TB}$ signs and symptoms or any cough.

In our study, nearly all bacteriologically confirmed $\mathrm{TB}$ cases in this study were initially suspected for abnormal CXR findings; less than $2 \%$ had a normal CXR-a finding consistent with other studies [40, 41]. WHO recommends the use of initial CXR followed by an acid-fast bacilli smear and Gene Xpert test if the CXR is abnormal [42]. In Myanmar, CXR and diagnostic radiologists are only available at township level hospitals covering an average population of around 150,000-200,000 [43]. With a TB prevalence of 242 per 100,000 population in 2018, annual CXR may be justifiable [44]. Given CXR is still not adequately available due to limitations of human and material resources as in other countries, a screening tool is needed for referring presumptive TB with symptoms to the health system [45].

Therefore, we analyzed the use of single or multiple TB symptoms as the rule-in criteria for the first TB screening step. Our findings revealed that over one third of TB cases had no TB symptoms, and conventional TBSS screening via any TB signs and symptoms had low sensitivity and specificity compared to CXR and social pathology characteristics screening tools. Having low sensitivity was because people were more likely to have low tolerance to tuberculosis signs and symptoms in response to TB infection $[46,47]$. On the other hand, having low specificity was more likely because the majority of those with tuberculosis signs and symptoms may have had other underlying conditions such as acute viral bronchitis, chronic bronchitis, and respiratory complications that lead to an overuse of diagnostic tests among individuals without TB [48-50].

Finally, in addition to TB-SS screening tools, development of new screening approach with prediction models have been increasingly used to improve TB case detection but did not perform any comparison to highlight the role of social pathological characteristics in TB screening $[28,51,52]$. We developed various TB screening models by using logistic regression analysis, and their performance on TB prediction was compared. Our proposed model of social pathology characteristics shows better calibration than combined models of social pathology characteristics and TB-SS and shows higher discrimination ability than TB-SS models. Many studies revealed that a useful screening tool is considered to have applied only when calibration and discrimination are good in performance [32, 37, 53].

All significant social pathology characteristic variables in the proposed social pathology model were consistent with the findings from the previous National TB prevalence survey in different countries [54-57]. However, our proposed social pathology model requires external validation in order to confirm that it predicts well in general population outside of our dataset. Assuming external validity, the decision-makers have to consider local needs by weighting sensitivity, specificity, and TB prevalence to choose appropriate cutoff value for TB prediction $[58,59]$. Our study shows that using propensity score cutoff value $\geq 0.0053$, which was driven from the significant social pathology characteristics, had a sensitivity of about $80 \%$ and specificity of nearly $70 \%$ to detect bacteriologically confirmed TB. Therefore, a 
Table 5 Social pathology predictor variables associated with bacteriologically confirmed TB and their population attributable fraction

\begin{tabular}{|c|c|c|c|c|c|}
\hline Covariates & $\begin{array}{l}\text { Bacteriologically } \\
\text { confirmed TB }(N=311)\end{array}$ & Crude odds ratio $(95 \% \mathrm{Cl})$ & Adjusted odds ratio $(95 \% \mathrm{Cl})$ & $p$ value & $\begin{array}{l}\text { Population attributable } \\
\text { fraction (\%) }\end{array}$ \\
\hline \multicolumn{2}{|l|}{ Age group (years) } & & & $<0.001$ & \\
\hline $15-24$ & 11 & Ref & Ref & & - \\
\hline $25-34$ & 52 & $4.9(2.5,9.4)$ & $6.2(3.2,11.9)$ & & 14.0 \\
\hline $35-44$ & 76 & $7.9(4.2,14.8)$ & $10.7(5.6,20.3)$ & & 22.2 \\
\hline $45-54$ & 66 & $8.5(4.5,16.2)$ & $10.9(5.7,20.8)$ & & 19.3 \\
\hline $55+$ & 106 & $12.2(6.5,22.7)$ & $11.1(5.9,20.9)$ & & 31.0 \\
\hline \multicolumn{2}{|l|}{ Gender } & & & $<0.001$ & \\
\hline Female & 105 & Ref & Ref & & - \\
\hline Male & 206 & $2.5(2.0,3.2)$ & $2.8(2.2,3.6)$ & & 42.6 \\
\hline \multicolumn{2}{|l|}{ Occupation } & & & $<0.001$ & \\
\hline Non farmer & 105 & Ref & Ref & & \\
\hline Farmer & 113 & $0.8(0.6,1.1)$ & $0.8(0.6,1.0)$ & & - \\
\hline Dependent & 93 & $1.4(1.1,1.9)$ & $1.5(1.1,2.1)$ & & 10.0 \\
\hline \multicolumn{2}{|l|}{ Religion } & & & 0.007 & \\
\hline Buddhist & 263 & Ref & Ref & & - \\
\hline Other & 48 & $2.0(1.5,2.8)$ & $1.6(1.1,2.3)$ & & 5.8 \\
\hline \multicolumn{2}{|c|}{ Rural and urban residences } & & & 0.004 & \\
\hline Rural & 208 & Ref & Ref & & - \\
\hline Urban & 103 & $1.7(1.3,2.2)$ & $1.5(1.2,2.0)$ & & 11.0 \\
\hline \multicolumn{2}{|l|}{ Regions and states } & & & $<0.001$ & \\
\hline Region & 192 & Ref & Ref & & - \\
\hline State & 119 & $1.6(1.2,2.0)$ & $1.6(1.2,2.0)$ & & 14.3 \\
\hline \multicolumn{2}{|l|}{ Contact with TB } & & & $<0.001$ & \\
\hline No & 265 & Ref & Ref & & - \\
\hline Yes & 44 & $2.3(1.6,3.2)$ & $2.0(1.4,2.8)$ & & 7.1 \\
\hline \multicolumn{6}{|l|}{ Previous history of TB } \\
\hline No & 269 & Ref & Ref & & - \\
\hline Yes & 42 & $5.5(3.9,7.7)$ & $2.8(1.9,3.9)$ & $<0.001$ & 8.7 \\
\hline \multicolumn{3}{|l|}{ Body mass index group } & & $<0.001$ & \\
\hline Underweight & 147 & $2.7(2.2,3.5)$ & $2.8(2.2,3.6)$ & & 30.4 \\
\hline Normal & 149 & Ref & Ref & & - \\
\hline Overweight/obese & 15 & $0.4(0.2,0.8)$ & $0.4(0.2,0.6)$ & & -6.0 \\
\hline
\end{tabular}

TB tuberculosis, $\mathrm{Cl}$ confidence interval

particle way to use the significant social pathology characteristics as a TB screening tool was to choose the appropriate propensity score cutoff value for TB prediction. After that, chest X-ray and sputum examinations should be performed for TB confirmation. Using the scoring system in the TB prediction has been documented in some studies [10,60,61].

Our study has several strengths in consideration of improving TB screening in the general population. Firstly, the predicted social pathology characteristics in our proposed TB screening model are easily measurable when conducting the community-based TB screening program. Secondly, the significant social pathology characteristics have strong evidence on association with TB in many diverse locations, indicating the important role of the social pathology characteristics on TB screening tool across the wide range of settings [54-57]. Thirdly, our study used large sample size of national TB prevalence survey data to develop and validate model in accordance with TRIPOD guideline [27].

Our study has some limitations. Firstly, all participants with both normal chest X-ray and without any TB signs 
Table 6 Overall performance, calibration, and discrimination ability of predicted propensity score in various TB screening models to predict bacteriologically confirmed TB

\begin{tabular}{|c|c|c|c|c|c|c|}
\hline \multirow{3}{*}{$\begin{array}{l}\text { Model performance } \\
\text { measures }\end{array}$} & \multicolumn{6}{|c|}{ Various TB screening models to predict bacteriologically confirmed TB } \\
\hline & \multicolumn{2}{|c|}{$\begin{array}{l}\text { Combined } \\
\text { models }\end{array}$} & \multirow{2}{*}{$\begin{array}{l}\text { Social pathology } \\
\text { model } \\
\text { C }\end{array}$} & \multicolumn{2}{|c|}{$\begin{array}{l}\text { TB-SS } \\
\text { models }\end{array}$} & \multirow{2}{*}{$\begin{array}{l}\text { Validated data of social pathology model (Bootstrap } \\
\text { resampling }=500) \\
\text { C }\end{array}$} \\
\hline & A & B & & $\mathbf{D}$ & E & \\
\hline \multicolumn{7}{|l|}{ Overall performance } \\
\hline Nagelkerke $\mathrm{R}^{2}$ & $12.9 \%$ & $11.8 \%$ & $11.5 \%$ & $2.7 \%$ & $0.6 \%$ & $11.9 \%(95 \%$ Cl 9.8-13.8\%) \\
\hline Brier score & 0.0059 & 0.0059 & 0.006 & 0.006 & 0.006 & $0.0058(95 \%$ Cl $0.005-0.006)$ \\
\hline \multicolumn{7}{|l|}{ Calibration } \\
\hline $\begin{array}{l}\text { Hosmer-Lemeshow } \\
\text { test }\end{array}$ & 0.005 & 0.604 & 0.787 & 1 & 1 & 0.502 \\
\hline Slope & 1 & 1 & 1 & 1 & 1 & 1 \\
\hline Intercept & 0 & 0 & 0 & 0 & 0 & 0 \\
\hline Eavg & 0.001 & 0.000 & 0.000 & 0.000 & 0.000 & $0.0006(95 \%$ Cl 0.0003-0.001) \\
\hline Emax & 0.190 & 0.138 & 0.093 & 0.000 & 0.000 & $0.126(95 \%$ Cl $0.03-0.295)$ \\
\hline \multicolumn{7}{|l|}{ Discrimination } \\
\hline$A \cup C$ & 81.7 & 80.7 & 80.5 & 63.7 & 55.2 & 80.8 (95\% Cl 78.3-83.0) \\
\hline DeLong $p$ value & 0.0136 & 0.3606 & Reference & 0.0001 & 0.0001 & \\
\hline Discrimination slope & 0.018 & 0.015 & 0.015 & 0.002 & 0.001 & $0.012(95 \%$ Cl 0.004-0.018) \\
\hline
\end{tabular}

Combined model A includes significant social pathology characteristics and any TB-SS variable. Combined model B includes significant social pathology characteristics and any cough variable. Model C includes significant social pathology characteristics. TB-SS model D includes any TB-SS variable. TB-SS model E include any cough variable

AUC area under the curve, Eavg average absolute error, Emax maximal absolute error, 95\% Cl 95\% confidence interval by bootstrap resampling $=500$

and symptoms were categorized as the healthy participants without preceding any confirmation test for TB. The negative result in the combined test of CXR and symptom screening does not need to conduct further testing, as TB prevalence in this group is very low, that is less likely to distort the sensitivity and specificity of our findings [23]. Secondly, we could not consider cost effectiveness of TB screening models that are also important for programmatic implementation.

Using the significant social pathology characteristics as the TB screening tool had good calibration and had improved the discrimination ability to $80.5 \%$, when
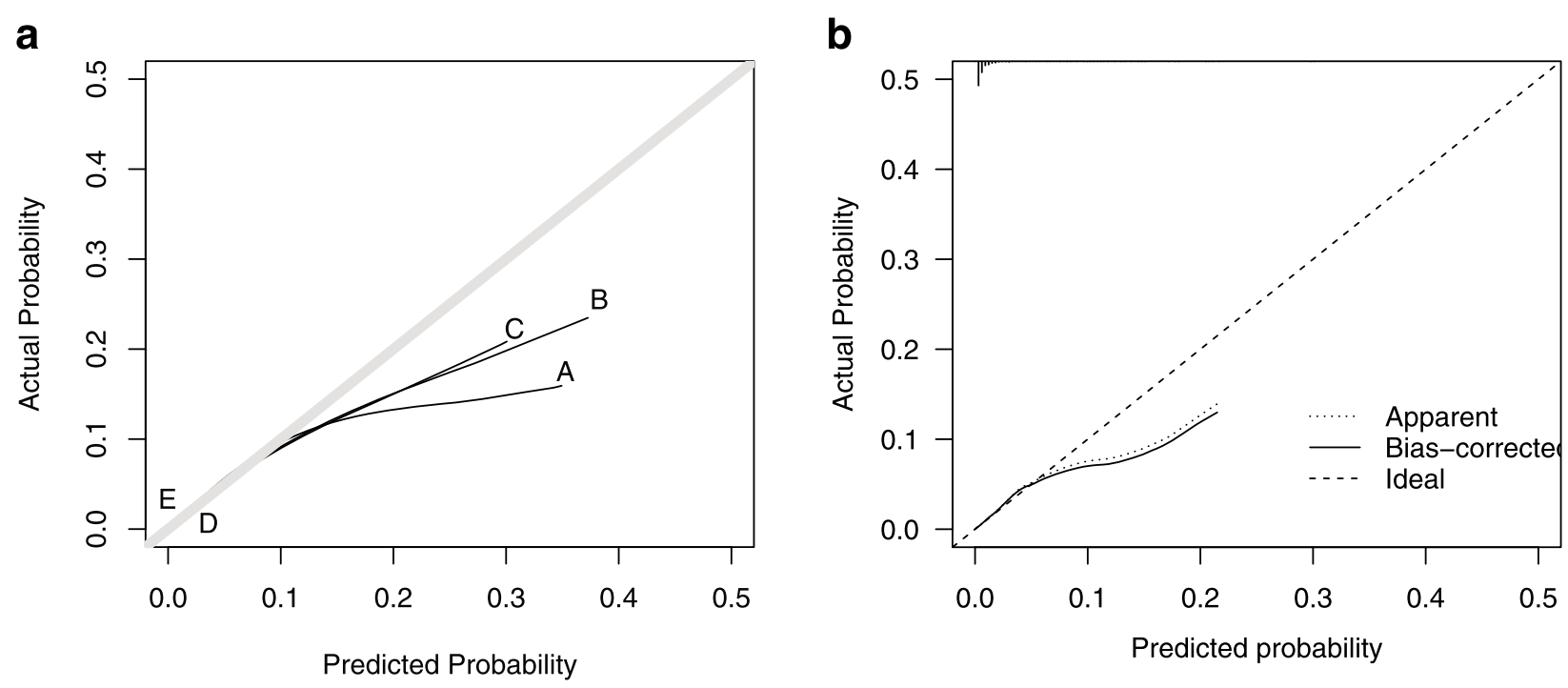

Fig. 2 a Calibration plot of various TB screening models A to E. b Calibration plot of validated data of social pathology model C (Bootstrap resampling=500) 

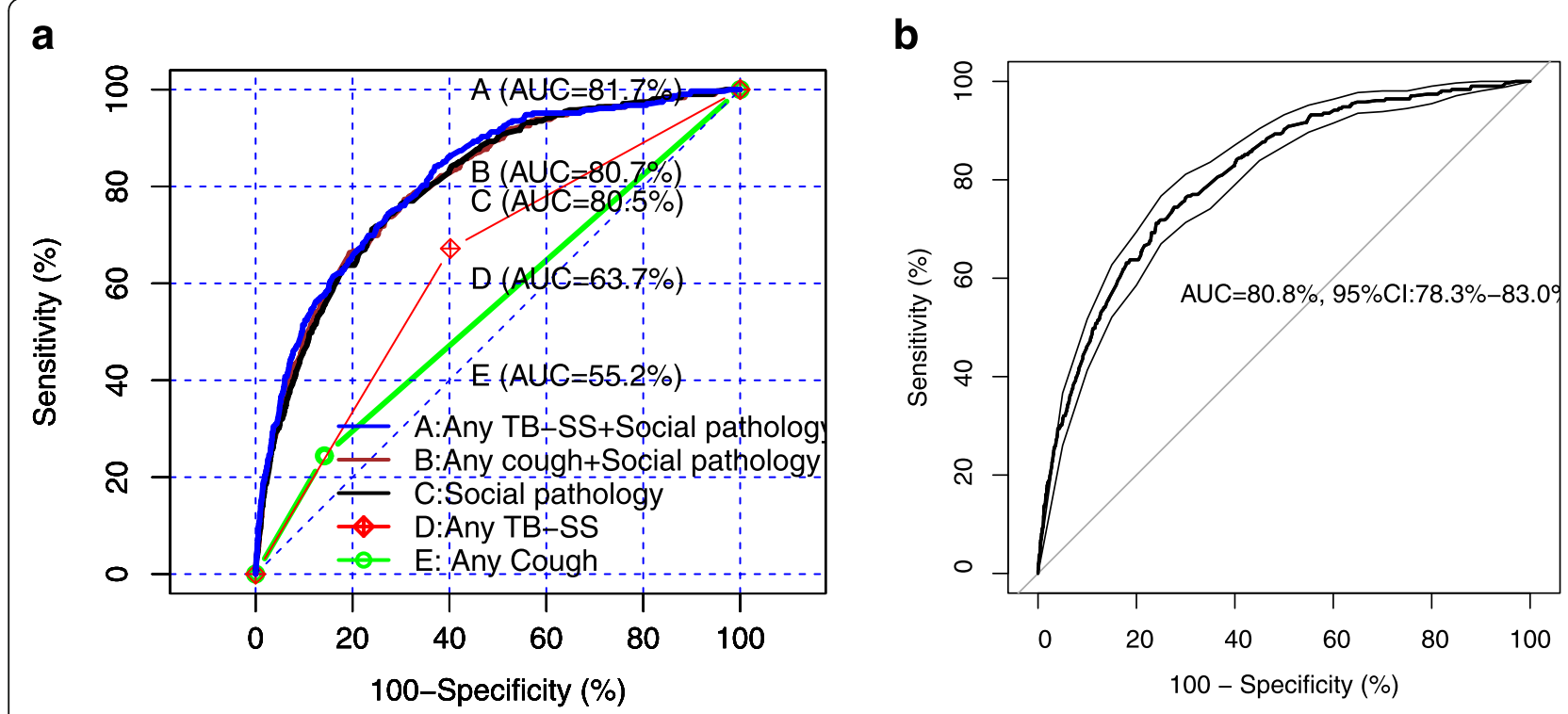

Fig. 3 a ROC curve of various TB screening models A to E. $\mathbf{b}$ ROC curve of validated data of social pathology model C (Bootstrap resampling=500)
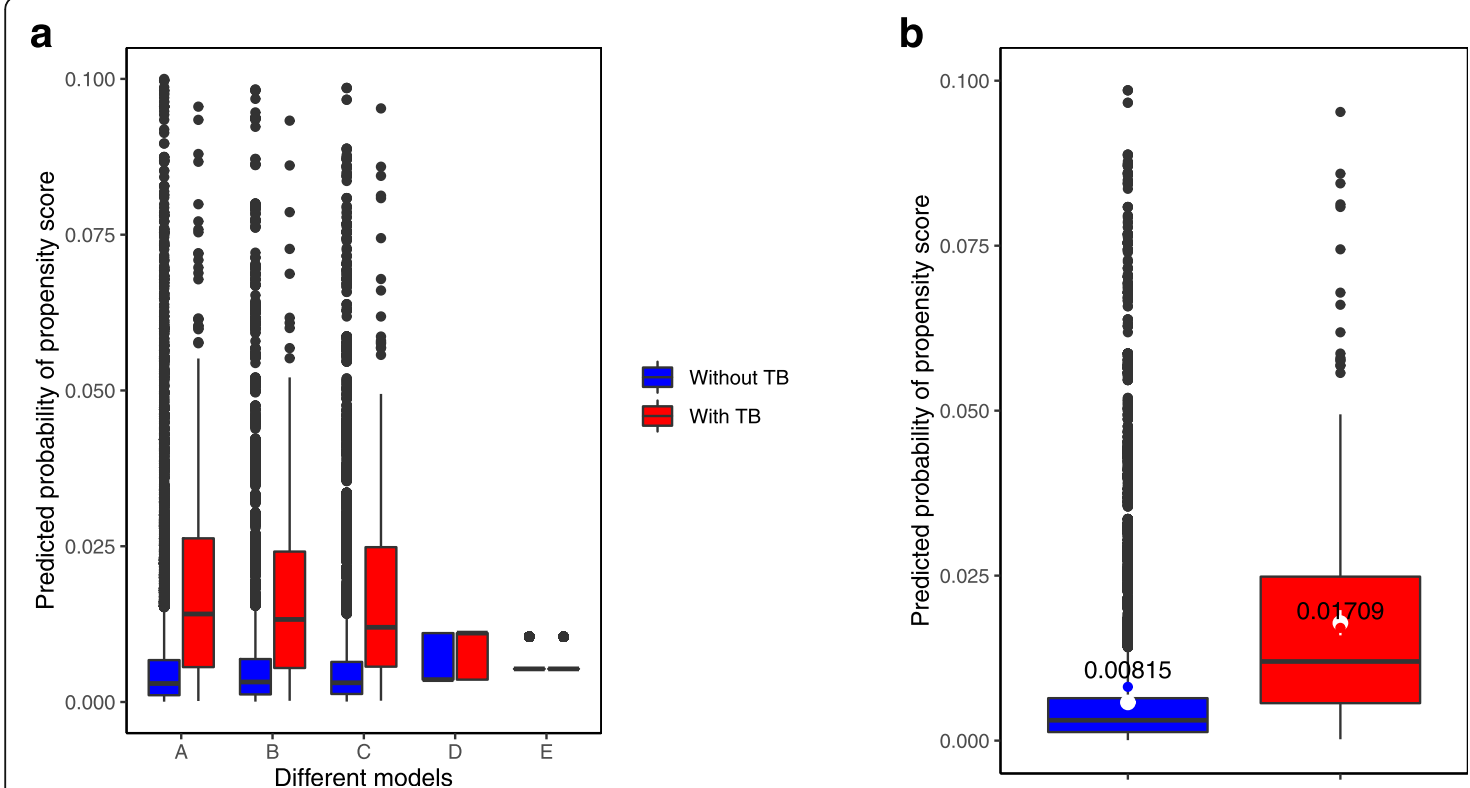

Fig. 4 a Discrimination box plot of various TB screening models A to E. b Discrimination box plot of social pathology model C (Bootstrap resampling=500) 
Table 7 Sensitivity, specificity, and positive likelihood ration to predict TB by different cutoff points of propensity score in various TB screening models

\begin{tabular}{|c|c|c|c|c|c|c|c|c|}
\hline \multirow{3}{*}{$\begin{array}{l}\text { Cutoff } \\
\text { points of } \\
\text { propensity } \\
\text { score }(<\text { vs } \\
\geq) \\
\end{array}$} & \multirow{3}{*}{$\begin{array}{l}\text { Total } \\
(N)\end{array}$} & \multicolumn{6}{|c|}{ Bacteriologically confirmed TB } & \multirow[t]{3}{*}{ Positive likelihood ratio } \\
\hline & & \multicolumn{3}{|c|}{ Positive $(N=311)$} & \multicolumn{3}{|c|}{ Negative $(N=51,056)$} & \\
\hline & & $\bar{n}$ & Sensitivity (\%) & $95 \% \mathrm{Cl}$ & $\bar{n}$ & Specificity (\%) & $95 \% \mathrm{Cl}$ & \\
\hline \multicolumn{9}{|c|}{ Combined model A } \\
\hline 0.001 & 39,230 & 299 & 97.0 & $94.0-98.0$ & 38,931 & 23.0 & $23.0-24.0$ & 1.3 \\
\hline 0.005 & 16,314 & 239 & 77.0 & $72.0-82.0$ & 16,075 & 68.0 & $68.0-69.0$ & 2.4 \\
\hline 0.0053 & 15,567 & 235 & 76.0 & $71.0-81.0$ & 15,332 & 70.0 & $69.0-70.0$ & 2.5 \\
\hline 0.01 & 7926 & 185 & 60.0 & $54.0-65.0$ & 7741 & 85.0 & $84.0-85.0$ & 3.9 \\
\hline 0.05 & 487 & 38 & 12.0 & $9.0-16.0$ & 449 & 99.0 & $98.9-99.9$ & 13 \\
\hline \multicolumn{9}{|c|}{ Combined model B } \\
\hline 0.001 & 39,688 & 300 & 97.0 & $95.0-99.0$ & 39388 & 22.0 & $22.0-23.0$ & 1.3 \\
\hline 0.005 & 17,504 & 245 & 79.0 & $74.0-84.0$ & 17259 & 66.0 & $65.9-66.9$ & 2.3 \\
\hline 0.0053 & 16,132 & 239 & 77.0 & $72.0-82.0$ & 15893 & 69.0 & $68.0-69.9$ & 2.5 \\
\hline 0.01 & 7547 & 176 & 57.0 & $51.0-63.0$ & 7371 & 85.0 & $85.0-86.0$ & 3.9 \\
\hline 0.05 & 441 & 27 & 9.0 & $6.0-12.0$ & 414 & 99.0 & 98.9-99.9 & 10.7 \\
\hline \multicolumn{9}{|l|}{ Model C } \\
\hline 0.001 & 40,546 & 301 & 97.0 & $95.0-99.0$ & 40,245 & 21.0 & $20.0-21.0$ & 1.2 \\
\hline 0.005 & 20,478 & 256 & 83.0 & $78.0-87.0$ & 20,222 & 60.0 & $60.0-61.0$ & 2.1 \\
\hline 0.0053 & 16,738 & 238 & 77.0 & $72.0-82.0$ & 16,500 & 68.0 & $67.0-68.9$ & 2.4 \\
\hline 0.01 & 8936 & 190 & 61.0 & $56.0-67.0$ & 8746 & 83.0 & $82.0-83.0$ & 3.6 \\
\hline 0.05 & 360 & 22 & 7.0 & $5.0-11.0$ & 338 & 99.0 & 89.9-99.9 & 10.7 \\
\hline
\end{tabular}

Combined model A includes significant social pathology characteristics and any TB-SS variable. Combined model B includes significant social pathology characteristics and any cough variable. Model $\mathrm{C}$ includes significant social pathology characteristics

comparing to $63 \%$ in using TB-SS, indicating the important role of the significant social pathology characteristics on TB screening. Our study highlights the need for improving the existing TB screening tool endorsed by the National Tuberculosis Programme, especially for the areas with the high prevalence of TB.

\section{Conclusions}

Incorporating the significant social pathology characteristics substantially improved the accuracy of TB screening. The National TB screening standard practice should therefore be changed accordingly.

\section{Abbreviations}

AIC: Akaike information criterion; AUC: Area under the curve; 95\% Cl: 95\% confidence interval; CXR: Chest x-ray; HIV: Human immunodeficiency virus; IQR: Interquartile range; ROC: Receiver operating characteristics; TB: Tuberculosis; TB-SS: Tuberculosis signs and symptoms

\section{Acknowledgements}

This study is a part of the thesis of KKKH in partial fulfillment of the requirement of a Degree of Doctor of Philosophy in Epidemiology at Prince of Songkla University under the sponsorship of Discipline of Excellence (Epidemiology).

The research reported in this publication was supported by the Fogarty International Center of the National Institutes of Health (NIH), Bethesda, MD, USA, on the project titled "TB/MDR-TB Research Capacity Building in lowand middle-income countries in Southeast Asia" (Award Number
D43TW009522) awarded to Virasakdi Chongsuvivatwong, Prince of Songkla University, Hat Yai, Songkhla, Thailand. The content is solely the responsibility of the authors and does not necessarily represent the official views of the $\mathrm{NIH}$.

Our sincere thanks are directed to the authorities from the National Tuberculosis Programme; Department of Public Health, Ministry of Health and Sports, Nay Pyi Taw; World Health Organization; and Department of Medical Research, Ministry of Health and Sports, for allowing us to conduct this research.

\section{Authors' contributions}

KKKH: conceptualization, development of study protocol, data collection, data analysis and interpretation, manuscript drafting, and final approval. VC: conceptualization, development of study protocol, data analysis and interpretation, manuscript drafting, and final approval. STA:

conceptualization, development of study protocol, manuscript drafting, and final approval.

\section{Funding}

Funding was not used to analyze secondary data of the National TB prevalence survey.

\section{Availability of data and materials}

The datasets used and/or analyzed during the current study are available from the National TB program, Myanmar, on reasonable request.

\section{Ethics approval and consent to participate}

The study was approved by the Institutional Review Board (IRB), Department of Medical Research, Myanmar, and the Institutional Ethics Committee of Faculty of Medicine, Prince of Songkla University, Hat Yai, Thailand. As this 
study used only the secondary data, the requirement of consent was waived by the Ethics Committee.

\section{Consent for publication}

Not applicable

\section{Competing interests}

The authors declare that they have no competing interests.

\section{Author details}

'Department of Medical Research, Ministry of Health and Sports, Pyin Oo Lwin, Myanmar. ${ }^{2}$ Epidemiology Unit, Faculty of Medicine, Prince of Songkla University, Hat Yai 90110, Thailand. ${ }^{3}$ Department of Public Health, Ministry of Health and Sports, Nay Pyi Taw, Myanmar.

\section{Received: 20 August 2020 Accepted: 21 December 2020} Published online: 07 January 2021

\section{References}

1. Macgregor AS. Tuberculosis and public health. Brit Med J. 1930;2:724-6.

2. $\mathrm{WHO}$ | Systematic screening for active tuberculosis: principles and recommendations. WHO. 2015 [cited 2019 Sep 27]; Available from: https:// www.who.int/tb/tbscreening/en/.

3. Cheng J, Wang $L$, Zhang $H$, Xia Y. Diagnostic value of symptom screening for pulmonary tuberculosis in China. PLoS One. 2015:10(5):1-10.

4. Onozaki I, Law I, Sismanidis C, Zignol M, Glaziou P, Floyd K. National tuberculosis prevalence surveys in Asia, 1990-2012: an overview of results and lessons learned. Trop Med Int Heal. 2015;20(9):1128-45.

5. van't Hoog AH, Langendam M, Mitchell E, Cobelens FG, Sinclair D, Leeflang $M M G$, et al. Symptom- and chest-radiography screening for active pulmonary tuberculosis in HIV-negative adults and adults with unknown HIV status. Cochrane Database Syst Rev. 2014;2014(1).

6. WHO | HIV-related TB deaths higher than past estimates. WHO. 2010 [cited 2019 Nov 21]; Available from: https://www.who.int/mediacentre/news/ releases/2009/tuberculosis_report_20090324/en/.

7. Harling G, Ehrlich R, Myer L. The social epidemiology of tuberculosis in South Africa: a multilevel analysis. Soc Sci Med. 2008;66(2):492-505. [cited 2019 Nov 22] Available from: https://www.sciencedirect.com/science/article/ abs/pii/S0277953607004844.

8. Hoa NB, Tiemersma EW, Sy DN, Nhung N V., Gebhard A, Borgdorff MW, et al. Household expenditure and tuberculosis prevalence in Vietnam: prediction by a set of household indicators. 2011 [cited 2019 Nov 22]; Available from: https://core.ac.uk/display/141609998.

9. Boccia D, Hargreaves J, Stavola BL De, Fielding K, Schaap A, GodfreyFaussett $P$, et al. The association between household socioeconomic position and prevalent tuberculosis in Zambia: a case-control study. PLoS One. 2011 [cited 2019 Nov 22];6(6). Available from: https://www.ncbi.nlm. nih.gov/pmc/articles/PMC3117783/.

10. Saunders MJ, Wingfield T, Tovar MA, Baldwin MR, Datta S, Zevallos K, et al. A score to predict and stratify risk of tuberculosis in adult contacts of tuberculosis index cases: a prospective derivation and external validation cohort study. Lancet Infect Dis. 2017;17(11):1190-9 [cited 2019 Nov 27] Available from: http://www.ncbi.nlm.nih.gov/pubmed/28827142.

11. Hargreaves JR, Boccia D, Evans CA, Adato M, Petticrew M, Porter JDH. The social determinants of tuberculosis: from evidence to action. Am J Public Health. 2011;101(4):654-662. [cited 2019 Nov 22] Available from: http:// www.ncbi.nlm.nih.gov/pubmed/21330583.

12. Frost WH. Risk of persons in familial contact with pulmonary tuberculosis. Am J Public Heal Nations Heal. 1933;23(5):426-32.

13. Narain R, Nair SS, Rao GR, Chandrasekhar P. Distribution of tuberculous infection and disease among households in a rural community. Bull World Health Organ. 1966:34(4):639-54.

14. Braun MM, Badi N, Ryder RW, Baende E, Mukadi Y, Nsuami M, et al. A retrospective cohort study of the risk of tuberculosis among women of childbearing age with HIV infection in Zaire. Am Rev Respir Dis. 1991;143(3): 501-4 [cited 2020 May 12] Available from: http://www.ncbi.nlm.nih.gov/ pubmed/2001057.

15. DeRiemer K, Kawamura LM, Hopewell PC, Daley CL. Quantitative impact of human immunodeficiency virus infection on tuberculosis dynamics. Am J Respir Crit Care Med. 2007;176(9):936-44.
16. Cegielski JP, McMurray DN. The relationship between malnutrition and tuberculosis: evidence from studies in humans and experimental animals. Int J Tuberc Lung Dis. 2004;8(3):286-98 [cited 2019 Nov 24] Available from: http://www.ncbi.n/m.nih.gov/pubmed/15139466.

17. Jeon CY, Murray MB. Diabetes mellitus increases the risk of active tuberculosis: a systematic review of 13 observational studies. PLoS Med. 2008;5(7):1091-101.

18. Muniyandi M, Ramachandran R, Gopi PG, Chandrasekaran V, Subramani R, Sadacharam $\mathrm{K}$, et al. The prevalence of tuberculosis in different economic strata: a community survey from South India. Int J Tuberc Lung Dis. 2007; 11(9):1042-5 [cited 2020 May 12] Available from: http://www.ncbi.n/m.nih. gov/pubmed/17705985.

19. Maurya V, Vijayan VK, Shah A. Smoking and tuberculosis: an association overlooked. Int J Tuberculosis Lung Disease. 2002;6:942-51.

20. Lönnroth K, Williams BG, Stadlin S, Jaramillo E, Dye C. Alcohol use as a risk factor for tuberculosis - a systematic review. BMC Public Health. 2008;8:289 [cited 2020 May 12] Available from: http://www.ncbi.nlm.nih.gov/pubmed/1 8702821.

21. Mishra VK, Retherford RD, Smith KR. Biomass cooking fuels and prevalence of tuberculosis in India. Int J Infect Dis. 1999;3(3):119-29.

22. World Health Organization. Global tuberculosis report 2017: leave no one behind - unite to end TB. WHO - Technical Report Series;727. 2017. 146 p. Available from: http://www.who.int/tb/publications/global_report/gtbr2017_ main_text.pdf?ua $=1$.

23. World Health Organisation. Chest radiography in tuberculosis. WHO Libr Cat Data. 2016;44. Available from: http://www.who.int/about/licensing/ copyright_form\%0Ahttp://www.who.int/about/licensing/copyright_form).

24. Douketis JD. Body weight classification. CMAJ. 2005 May 10 [cited 2019 Sep 30];172(10):1274-5; author reply 1275. Available from: http://www.ncbi.nlm. nih.gov/pubmed/15883391.

25. RStudio: integrated development environment for R. [cited 2020 Jun 11]. Available from: https://www.kdnuggets.com/2011/03/rstudio-ide-for-r.html.

26. Bootstrap confidence intervals for sensitivity of a quantitative diagnostic test | Request PDF. [cited 2020 Jun 11]. Available from: https://www. researchgate.net/publication/12665894_Bootstrap_confidence_intervals_for_ sensitivity_of_a_quantitative_diagnostic_test.

27. Collins GS, Reitsma JB, Altman DG, Moons KGM. Transparent reporting of a multivariable prediction model for individual prognosis or diagnosis (TRIPOD) the TRIPOD statement. Circulation. 2015;131(2):211-9.

28. Ghazvini K, Yousefi M, Firoozeh F, Mansouri S. Predictors of tuberculosis: application of a logistic regression model. Gene Reports. 2019;17:100527.

29. Miettinen OS. Proportion of disease caused or prevented by a given exposure, trait or intervention. Am J Epidemiol. 1974;99(5):325-32 [cited 2019 Nov 24] Available from: http://www.ncbi.nlm.nih.gov/pubmed/4825599.

30. Propensity score / Columbia University Mailman School of Public Health. [cited 2020 Jan 20]. Available from: https://www.mailman.columbia.edu/ research/population-health-methods/propensity-score.

31. Rosenbaum PR, Rubin DB. Reducing bias in observational studies using subclassification on the propensity score. J Am Stat Assoc. 1984;79(387):516 [cited 2020 Jun 11] Available from: https://www.jstor.org/stable/2288398.

32. Steyerberg EW, Vickers AJ, Cook NR, Gerds T, Gonen M, Obuchowski N, et al. Assessing the performance of prediction models: a framework for traditional and novel measures. Epidemiology. 2010;21:128-38.

33. NJD N. A note on a general definition of the coefficient of determination. Biometrika. 1991;78(3):691-2 Available from: https://doi.org/10.1093/biomet/ 78.3.691.

34. Gerds TA, Cai T, Schumacher M. The performance of risk prediction models. Biom J. 2008:50:457-79.

35. Hilden J, Habbema JDBB. The measurement of performance in probabilistic diagnosis. II. Trustworthiness of the exact values of the diagnostic probabilities. Methods Inf Med. 1978;17(4):227-37.

36. Miller ME, Langefeld CD, Tierney WM, Hui SL, Mcdonald CJ. Validation of probabilistic predictions. Med Decis Mak. 1993;13(1):49-57.

37. Wang S. Development of a predictive model of tuberculosis transmission among household contacts. Ricci ML, editor. Can J Infect Dis Med Microbiol. 2019;2019:5214124. Available from: https://doi.org/10.1155/2019/5214124.

38. Hosmer DW, Jr., Lemeshow S. Applied logistic regression. John Wiley \& Sons; 2004 [cited 2020 Jun 11]. 392 p. Available from: http://books.google. $\mathrm{com} /$ books?hl=en\&lr=\&id=PoORLQ7USIMC\&pgis=1.

39. Yates JF. External correspondence: decompositions of the mean probability score. Organ Behav Hum Perform. 1982;30(1):132-56. 
40. Den Boon S, White NW, Van Lill SWP, Borgdorff MW, Verver S, Lombard CJ, et al. An evaluation of symptom and chest radiographic screening in tuberculosis prevalence surveys. Int J Tuberc Lung Dis. 2006;10(8):876-82.

41. Pepper T, Joseph P, Mwenya C, McKee G-S, Haushalter A, Carter A, et al. Normal chest radiography in pulmonary tuberculosis: implications for obtaining respiratory specimen cultures. [cited 2019 Oct 8]; Available from: https://www.ingentaconnect.com/content/iuatld/ijtld/2008/00000012/ $00000004 / a r t 00010$

42. World Health Organization. Systematic screening for active tuberculosis. Principles and Recommendations. 2013;

43. Than Tun Sein,Phone Myint AC. How can the township health system be strengthened in Myanmar? Myanmar Health Systems in Transition Policy. 2014 [cited 2020 Jul 12]. Available from: https://www.3mdg.org/sites/3mdg. org/files/publication_docs/myanmar_pns3_en_0.pdf.

44. Aung ST. Results of nationwide TB prevalence survey Myanmar. 2019;(April): 1-28. Available from: https://www.myanmarhscc.org/wp-content/uploads/2 019/09/1.-Dr.-STA_PrevSurveyResultsSummary.pdf.

45. van der Werf MJ, Enarson DA, Borgdorff MW. How to identify tuberculosis cases in a prevalence survey. 2008 [cited 2019 Oct 8]; Available from: https://core.ac.uk/display/141584397.

46. Salgame P, Geadas C, Collins L, Jones-López E, Ellner JJ. Latent tuberculosis infection - revisiting and revising concepts. Tuberculosis. 2015;95(4):373-84 [cited 2019 Nov 26] Available from: https://www.sciencedirect.com/science/ article/abs/pii/S1472979214206792.

47. Miller LG, Asch SM, Yu El, Knowles L, Gelberg L, Davidson P. A populationbased survey of tuberculosis symptoms: how atypical are atypical presentations? Clin Infect Dis. 2000;30(2):293-9 [cited 2019 Sep 27] Available from: http://www.ncbi.n/m.nih.gov/pubmed/10671331.

48. Kim L, Heilig CM, McCarthy KD, Phanuphak N, Chheng P, Kanara N, et al. Symptom screen for identification of highly infectious tuberculosis in people living with HIV in Southeast Asia. J Acquir Immune Defic Syndr. 2012;60(5):519-24 [cited 2019 Nov 26] Available from: http://www.ncbi.nlm. nih.gov/pubmed/22487587.

49. Rosen MJ. Chronic cough due to tuberculosis and other infections: ACCP evidence-based clinical practice guidelines. Chest. 2006;129(1):197S-201S [cited 2019 Nov 26] Available from: https://www.sciencedirect.com/science/ article/abs/pii/S0012369215528493.

50. Golub JE, Mohan Cl, Comstock GW, Chaisson RE. Active case finding of tuberculosis: historical perspective and future prospects. Vol. 9, International Journal of Tuberculosis and Lung Disease. NIH Public Access; 2005 [cited 2020 Jun 25]. p. 1183-203. Available from:https://www.ncbi.nlm.nih.gov/ pmc/articles/PMC4472641/.

51. Van Wyk SS, Lin HH, Claassens MM. A systematic review of prediction models for prevalent pulmonary tuberculosis in adults. Int J Tuberculosis Lung Dis 2017;21 405-411.

52. de Castro CBA, da Costa PA, Ruffino-Netto A, Maciel ELN, Kritski AL. Assessment of a clinical score for screening suspected pulmonary tuberculosis cases. Rev Saude Publica. 2011;45(6):1110-1116. [cited 2020 Jun 25] Available from: https://pubmed.ncbi.n/m.nih.gov/21953078/.

53. Wang S. Development of a predictive model of difficult hemostasis following endobronchial biopsy in lung cancer patients. 2019 [cited 2020 Jun 25]; Available from: https://doi.org/10.1155/2019/1656890.

54. Dhanaraj B, Papanna MK, Adinarayanan S, Vedachalam C, Sundaram V, Shanmugam $\mathrm{S}$, et al. Prevalence and risk factors for adult pulmonary tuberculosis in a metropolitan city of south India. PLoS One. 2015;10(4). e0124260. pmid:25905900.

55. Siroka A, Law I, Macinko J, Floyd K, Banda RP, Hoa NB, et al. The effect of household poverty on tuberculosis. Int J Tuberc Lung Dis. 2016; 20(12):1603-8.

56. Petersen AB, Muffley N, Somsamouth K, Singh PN. Smoked tobacco, air pollution, and tuberculosis in lao PDR: findings from a national sample. Int J Environ Res Public Health. 2019;16(17):3059

57. Shih Y-J, Ayles H, Lönnroth K, Claassens M, Lin H-H. Development and validation of a prediction model for active tuberculosis case finding among HIV-negative/unknown populations. Sci Rep. 2019;9(1):6143.

58. Moreira J, Bisig B, Muwawenimana P, Basinga P, Bisoffi Z, Haegeman F, et al. Weighing harm in therapeutic decisions of smear-negative pulmonary tuberculosis. Med Decis Making. 29(3):380-90 [cited 2020 Jan 20] Available from: http://www.ncbi.n/m.nih.gov/pubmed/19224870.

59. Sreeramareddy CT, Rahman M, Harsha Kumar HN, Shah M, Hossain AM, Sayem MA, et al. Intuitive weights of harm for therapeutic decision making in smear-negative pulmonary tuberculosis: an interview study of physicians in India, Pakistan and Bangladesh BMC Med Inform Decis Mak. 2014;14(1):67.

60. Saunders MJ, Wingfield T, Datta S, Montoya R, Ramos E, Baldwin MR, et al. A household-level score to predict the risk of tuberculosis among contacts of patients with tuberculosis: a derivation and external validation prospective cohort study. Lancet Infect Dis. 2019[cited 2020 Jan 6]; Available from: http://www.ncbi.nlm.nih.gov/pubmed/31678031.

61. Mandalakas AM, Kirchner HL, Lombard C, Walzl G, Grewal HMS, Gie RP, et al Well-quantified tuberculosis exposure is a reliable surrogate measure of tuberculosis infection. Int J Tuberc Lung Dis. 2012;16(8):1033-9.

\section{Publisher's Note}

Springer Nature remains neutral with regard to jurisdictional claims in published maps and institutional affiliations.
Ready to submit your research? Choose BMC and benefit from:

- fast, convenient online submission

- thorough peer review by experienced researchers in your field

- rapid publication on acceptance

- support for research data, including large and complex data types

- gold Open Access which fosters wider collaboration and increased citations

- maximum visibility for your research: over $100 \mathrm{M}$ website views per year

At BMC, research is always in progress.

Learn more biomedcentral.com/submissions 